\title{
Erratum to: DNA origami mediated electrically connected metal- semiconductor junctions
}

Basu R. Aryal ${ }^{1}$, Dulashani R. Ranasinghe ${ }^{1}$, Tyler R. Westover ${ }^{3}$, Diana G. Calvopiña ${ }^{1}$, Robert C. Davis ${ }^{3}$, John N. Harb², and Adam T. Woolley ${ }^{1}(\square)$

${ }^{1}$ Department of Chemistry and Biochemistry, Brigham Young University, Provo, UT 84602, USA

${ }^{2}$ Department of Chemical Engineering, Brigham Young University, Provo, UT 84602, USA

${ }^{3}$ Department of Physics and Astronomy, Brigham Young University, Provo, UT 84602, USA

(C) Tsinghua University Press and Springer-Verlag GmbH Germany, part of Springer Nature 2021

\section{Erratum to}

Nano Research 2020, 13(5): 1419-1426

https://doi.org/10.1007/s12274-020-2672-5

Figure 8(f) was unfortunately mistakenly used. The two duplicate graphs were among several examples of the type of data the authirs obtained in those experiments, so this error did not affect any of the conclusions from the published paper.

\section{Instead of}

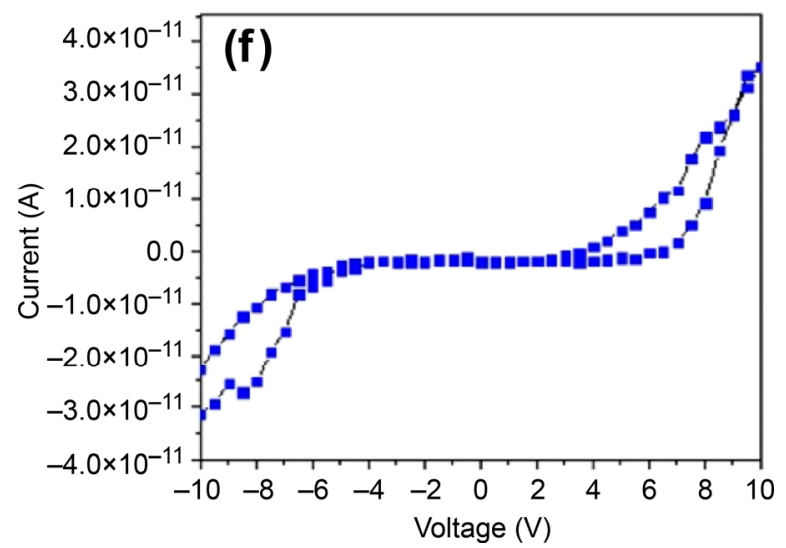

The online version of the original article can be found at

https://doi.org/10.1007/s12274-020-2672-5
It should be changed to

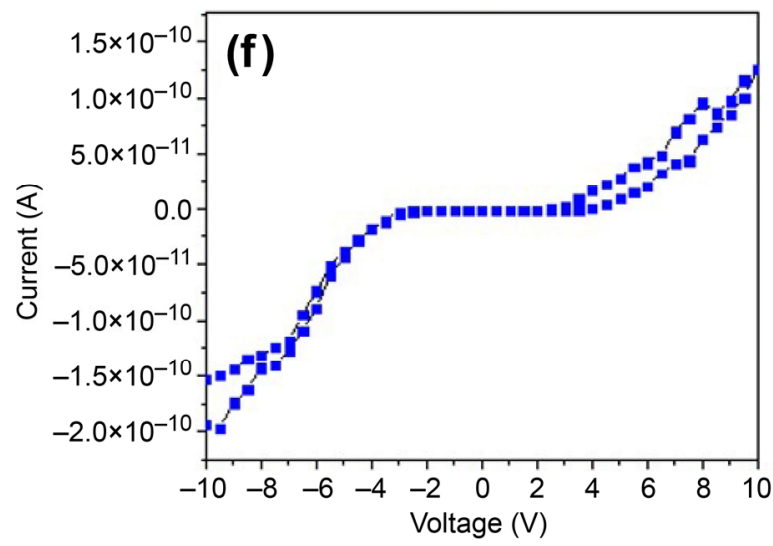

